doi: $\underline{\text { http://dx.doi.org/10.5892/RUVRV.91.5265 }}$

\title{
UMA ANÁLISE DA FUNDAMENTAÇÃO DAS DECISÕES JURÍDICO ADMINISTRATIVAS DO ESTADO
}

\author{
Eloy Pereira LEMOS JÚNIOR ${ }^{1}$ \\ Ludmila Castro Veado STIGERT ${ }^{2}$ \\ Thiago Augusto de FREITAS ${ }^{3}$
}

\begin{abstract}
Sumário: 1 - Introdução. 2 - A interpretação no jusnaturalismo e sua superação pelo positivismo. 3 - A interpretação no pós-positivismo. 3.1 - A ausência de fundamentação e o "trilema de Munchhasen". 3.2 - Argumentos institucionais e não institucionais. $3.3 \mathrm{O}$ princípio da proporcionalidade e sua inaplicabilidade como fundamentação da decisão. 4 Considerações finais. 5 - Referências.
\end{abstract}

RESUMO: O presente artigo busca elucidar, de uma maneira sintética, a evolução da interpretação jurídica, desde seus primórdios jusnaturalistas até o seu ápice evolutivo com o Pós positivismo jurídico. Entretanto, destacou-se também, que a atividade interpretativa precisa basear-se em argumentos racionais e principiológicos, superando-se a vertente objetivista que compreendia o ato interpretativo como algo mecânico, subsuntivo e atrelado à letra fria da lei. Nesse contexto, destaca-se a necessidade imperiosa de fundamentação racional das decisões, sejam elas de cunho judicial ou administrativo, ao invés de pautá-las em argumentos vagos e abertos, como o Princípio da Proporcionalidade ou Princípio da Supremacia do Interesse Público. O Estado Democrático de Direito requer do operador do Direito uma postura condizente e adequada aos parâmetros da legitimidade democrática das decisões.

Palavras Chave: Interpretação. Jusnaturalismo. Positivismo Jurídico. Pós Positivismo jurídico. Fundamentação racional. Princípio da Proporcionalidade.

ABSTRACT: The article shows, in the succint form, an interpretation for the Law, since jusnaturalism until Pos Positivism. Bside that, it claims for the necessity of the racional and principle argue for the activity of interpretation. In this way, the objective form of interpretation could be surtassed for the new arguments. For that, detach the necessity of racional reasons in to the decisions, judicial or administractive, instead of open words, like that Proporcionality Principle or Principle of Supremacy of Public Interest. The Democratic State requires from the applicator of Law an appropriate posture from the parameter of the legitimacy democratic decisions.

Key words: Interpretation. Jusnaturalism. Positivism. Pos Positivism. Racional reasons. Proporcionality Principle.

${ }^{1}$ Bolsista da CAPES na Faculdade de Direito da Universidade "Clássica" de Lisboa - Portugal. Professor Titular nos
Cursos de Direito das Faculdades: FAMINAS-BH, FACED-Divinópolis, UNIPAC-Bom Despacho, FADIPA-Ipatinga,
PITÁGORAS-Betim e FADIPA/UEMG-Passos (liçenciado).
${ }^{2}$ Professora de Teoria Geral do Estado e Ciência Política, Direito Constitucional e Direito Internacional Público da
FAMINAS-BH. Professora de Teoria da Constituição do Centro Universitário Newton Paiva. Professora de Teoria
Geral do Estado da Pós-graduação da PUC-Minas (IEC). Coordenadora do Trabalho Interdisciplinar Supervisionado e
Pesquisadora Institucional da Faculdade de Minas/FAMINAS-BH. Mestre em Direito Público pela Pontifícia
Universidade Católica de Minas Gerais/PUC-MINAS. Especialista em Processo Constitucional pelo Centro
Universitário Izabela Hendrix/IHENDRIX. Especialista em Direito Público pelo Centro Universitário Newton Paiva.
${ }_{\text {3raduado em Direito pela PUC-MG; Professor substituto de prática processual da PUC-MG; Membro da Comissão de }}$
Defesa do Consumidor da OAB/MG; Advogado sócio do Torres, Oliveira, Ribeiro \& Freitas Sociedade de Advogados. 52

Revista da Universidade Vale do Rio Verde, Três Corações, v. 9, n. 1, p. 52-65, jan./jul. 2011 


\section{INTRODUÇÃO}

A fundamentação das decisões é imperativo constitucional e decorrência lógica do Estado Democrático de Direito. Apesar disso, não são raras as decisões do Estado que apresentam ausência de fundamentação lógica, constitucional e subjetivamente controláveis, o que fere os preceitos do paradigma do Estado Democrático de Direito.

Exemplo desse fato são decisões que invocam dogmas jurídicos, como a aplicação irracional do Princípio da Supremacia do Interesse Público sobre o Privado, entendido como a prevalência da vontade da coletividade sobre o Direito individual, ou mesmo em expressões de incerta conceituação e abertura interpretativa, como vontade popular e paz social.

Todavia, tal forma de atuar do Estado não é fenômeno recente. Nesse sentido, é interessante fazer uma pequena digressão sobre a questão da fundamentação das decisões do Estado, passando pelo jusnaturalismo, pelo positivismo até chegarmos no pós-positivismo constitucional.

Nessa seara, observa-se que, no Estado Democrático de Direito, torna-se cada vez mais necessária a constituição de uma argumentação pautada em argumentos subjetivamente controláveis, oriundos de mecanismos lógicos de interpretação e de um discurso racionalmente adequado.

\section{A interpretação no jusnaturalismo e sua} superação pelo positivismo

A crença no Direito natural, ou seja, na concepção de que o homem era dotado de Direitos inatos, inalienáveis e impossíveis de serem supridos pelos governantes, foi um dos grandes comburentes das revoluções burguesas do século XVIII. Isso, porque acreditavam os jusnaturalistas na existência de valores e de pretensões humanas legítimas que não decorriam de uma norma emanada do Estado. O Direito natural sempre fora interpretado pelos defensores dessa teoria como superior ao Direito positivo, era um Direito absoluto e universal por corresponder à natureza humana.

Com a ascensão do Estado Liberal e com a conseqüente inclusão de tais Direitos no campo normativo, mais precisamente com as declarações de Direitos, verifica-se o apogeu dos Direitos naturais e, paradoxalmente, a sua superação histórica, posto que surge o pensamento positivista e o Direito natural passa a ser considerado como metafísico e anti-científico. Nesse contexto, Auguste Comte eleva o positivismo como à máxima condição de obtenção do conhecimento.

$\mathrm{O}$ positivismo leva às ultimas conseqüências o papel reservado à razão de descobrir as relações constantes e necessárias 
entre os fenômenos, ou seja, as leis invariáveis que os regem. Para os positivistas somente a ciência era capaz de discernir o que tem de ser e não pode deixar de ser. (ARANHA, 1993).

Este ideário de pensamento científico teve ressonância direta no Direito, surgindo assim, o positivismo jurídico, o qual teve como premissa basilar a criação de uma ciência jurídica, como aquela aplicável às ciências exatas.

No positivismo jurídico houve o nítido afastamento do Direito das questões morais, uma vez que o Direito fora reduzido à norma emanada pelo Estado com força coercitiva. O interprete do Direito deveria pautar-se tão somente em juízos de fato e, de forma alguma, em juízos de valor. Assim, somente existia Direito dentro das normas emanadas pelo Estado.

Pelas elucidações trazidas, pôde-se perceber que o positivismo jurídico tinha como escopo principal a estrita vinculação do interprete ao texto literal da lei, ou seja, a ele não caberia qualquer tipo de interpretação ou aplicação de outros meios de julgamento, a não ser a aplicação das regras jurídicas (aplicação silogística).

A aplicação da norma, destarte, faziase pelo método subsuntivo de adequação dos fatos à norma. Nesse viés, o dever do juiz consistia tão somente em "revelar" a vontade da norma, desempenhando uma atividade de mero conhecimento, sem envolver qualquer parcela de criação do Direito para o caso concreto. (BARROSO e BARCELOS, 2003).

Com efeito, tal mecanismo de aplicação do Direito deixava a sociedade à mercê das leis muitas vezes despóticas, abrindo assim caminho para os governos ditatoriais, como no caso do fascismo e nazismo, por exemplo. Isso porque, ao interprete da lei era ordenado tão somente a subsunção do fato à norma, não podendo existir qualquer tipo de valoração de princípios, o que tornava o magistrado e os operadores do Direito meros reprodutores da vontade do legislador que, em tais Estados de Polícia, era a extensão da vontade plena do governante.

A usurpação do Direito por meio do positivismo jurídico teve maior ressonância nos governos ditatoriais como os nazistas, os quais elevaram o poder dentro do quadro de legalidade vigente e promoveram barbáries em nome da lei.

Após a derrocada de tais movimentos políticos e logo após a Segunda Guerra Mundial a idéia de um ordenamento jurídico indiferente a valores éticos e da lei como uma estrutura meramente formal, uma embalagem para qualquer produto, já não tinha mais aceitação no pensamento esclarecido. (BARROSO e BARCELOS, 2003).

Destarte, era necessário que surgisse um novo mecanismo de interpretação constitucional que, ao mesmo tempo em que desse guarida aos preceitos normativos, aplicasse-os de forma mais humana, 
valorizando os princípios norteadores do Direito. Dentro dessa necessidade, surge assim uma nova metódica interpretativa do sistema do Direito, que teve como pano de fundo a abertura discursiva ao sistema operacional do direito, até agora denominada de pós-positivismo.

\section{A INTERPRETAÇÃO NO PÓS- POSITIVISMO}

No pós-positivismo, as cláusulas constitucionais não se prestam ao sentido unívoco e objetivo que uma certa autoridade política lhe pretenda dar. O relato da norma, muitas vezes, demarca apenas uma moldura dentro da qual se desenham diferentes possibilidades interpretativas. Para a aferição de qual Direito deve ser aplicado, dever-se-á analisar em cada caso todas as possibilidades de aplicação das normas, os princípios norteadores do Direito e, sempre, orientandose pela partitura constitucional.

Neste norte, para a devida aplicação da nova interpretação constitucional, fez-se necessária, primeiramente, a superação da idéia de que os princípios constitucionais tinham apenas um caráter axiológico, ético, sem qualquer vinculação na aplicação do Direito, ou seja, teve que elevar os princípios ao caráter de norma jurídica.

Primordial para tal acontecimento foi à distinção realizada pela doutrina entre as regras e princípios constitucionais. Os princípios apenas estabelecem o ponto de partida ou metas genéricas, ao contrário das regras que se aplicam ou não ao fato. Os princípios não são aplicáveis a maneira de um "tudo ou nada", pois enunciam uma ou alguma razões para decidir um determinado sentido, já as regras enunciam pautas dicotômicas, isto é, estabelecem as condições que tornam necessária sua aplicação e conseqüências que se seguem necessariamente. Os princípios têm um peso ou importância relativa, pois comportam avaliação sem que a substituição de um por outro de maior peso signifique a exclusão do primeiro, o que não ocorre com as regras as quais quando contraditadas provocam a exclusão do dispositivo colidente. Destarte, o conceito de validade cabe bem para as regras (que são válidas ou não), mas para os princípios, que, por serem submetidos à validade de importância, mais bem se encaixam ao conceito de legitimidade. (FERRAZ JÚNIOR, 2003)

Pelas peculiaridades das definições das regras, percebe-se que em um eventual conflito, menos árdua é a resolução do mesmo, posto que, seja por competência legislativa, seja por inconstitucionalidade, dever-se-ia aplicar apenas uma das regras no caso concreto.

O grande problema se faz quando colidem dois princípios, como, por exemplo, no caso de possível colisão em um caso concreto do Principio da Supremacia do Interesse Público face ao Individual e da supremacia dos Direitos Fundamentais. 
É exatamente neste ponto, colisão de normas, que emerge a necessidade de existir no decidir do Estado um argumento lógico capaz de fundamentar a decisão exarada, não bastando apenas suscitar a existência de uma supremacia a priori, ou seja, argumentação racionalmente orientada(pautada) por princípios constitucionais.

Neste ínterim, é sabido que os paradigmas jurídicos vigentes à época possuem enorme interferência na forma de se interpretar as normas (princípios e regras).

Nota-se, atualmente, que no atuar do Estado, seja no âmbito administrativo ou na seara judicial, constante é a aplicação fria e $a$ priori de um princípio ou regra sobre outro. Tal prática é disseminada sem a devida análise do caso concreto e de sua validade, destoando completamente da nova interpretação constitucional, utilizando na maioria das vezes de argumentos desprovidos de validade jurídica, fator este que traz inúmeros prejuízos e levam a atuação Estatal a um decisionismo desvinculado de legalidade e de racionalidade discursiva.

No Estado Democrático de Direito, como traçado, não mais pode existir a aplicação irracional do Direito, muito menos a simples invocação de pré-concepções dogmáticas afastadas da análise sistemática do ordenamento jurídico, como outrora ocorria no positivismo jurídico.

Comumente, constata-se que a supremacia de um principio ou de uma regra sobre outro(a) serve-se para justificar atuações da administração pública ou, tão somente, para cessar uma discussão de Direitos e interesses, invocando um princípio/norma que pela sua gênese torna completamente impossível a existência de discussão ou ponderação de interesses, métodos estes impróprios na nova sistemática de interpretação constitucional.

\subsection{A ausência de fundamentação e o "trilema de Munchhasen"}

A aplicação irracional, ilógica, capaz de evitar, ou melhor, cessar qualquer argumento contrário à sua aplicabilidade, enquadra-se claramente no Trilema de Münchhausen $^{4}$, desenvolvido por Hans Albert, em seu livro Tratado da Razão Crítica (1976). Para o autor, qualquer argumento válido somente pode ser aferido através da dedução lógica, aplicável claramente ao problema da fundamentação, a qual tem como escopo, em cada caso, assegurar a verdade das concepções em questão e, dessa forma, a dos enunciados com os quais elas se formulam. A verdade - o valor positivo da verdade somente seria alcançada por meio de uma dedução lógica. (ALBERT, 1976).

Continuando seu raciocínio, o autor (1976) alude ao fato de que o não agir da

4 Teoria sobre a racionalidade dos argumentos na fundamentação trazido a lume pelo Professor Dhenis Cruz Madeira, em aula ministrada na disciplina Prática Jurídica III, na Faculdade Mineira de Direito da Pontifícia Universidade Católica de Minas Gerais, unidade Contagem, no dia 19 de março de 2009. 
forma lógica mencionada, fatalmente levará ao intérprete a três possibilidades inaceitáveis, denominando-as de regresso ao infinito, a um círculo lógico e a uma interrupção abrupta do conhecimento, sendo esses os núcleos do trilema.

O regresso ao infinito consiste no fato de que o interprete, para fundamentar sua alegação, necessita, a todo o momento, retornar incessantemente na busca de fundamentos, mas, que na prática, não é passível de realização e não proporciona nenhuma base segura. Já no que discerne a um círculo lógico, verifica-se que ao fundamentar seu arrazoado, o interprete retoma, no processo de fundamentação, de enunciados que já surgiram anteriormente como carentes de fundamentação, e o qual, por ser logicamente falho, conduz do mesmo modo a nenhuma base segura. Por fim, verifica-se que não havendo mais nenhuma "saída" lógica para o intérprete, este usa de uma ruptura abrupta do conhecimento, utilizando-se de uma suposta verdade já posta, um dogma. (ALBERT, 1976).

Diferente não é, muitas vezes, na aplicação fria de um princípio onde inexiste, na maioria das vezes, uma discussão do Estado quanto o que seria a supremacia do princípio e qual seria, de fato, as razões para a sua aplicação.

Pelo contrário, tido como máxima, a aplicação fria e a priori de um princípio/norma tem como uma de suas funções, exatamente, a ruptura da análise racional de sua necessária aplicação por meio da invocação do dogma de superioridade.

Assim coaduna o autor:

[...] uma convicção ou enunciado que não pode ser fundamentado por si só, mas que atua na fundamentação de todos os outros, e que é colocado como seguro, embora em princípio se possa pôr em dúvida tudo - e até ele mesmo - então esta seria uma afirmação, cuja verdade é certa e por isso não carece de fundamentação, ou seja, um dogma, então a nossa terceira possibilidade se resume naquilo que não se deveria esperar na solução do problema da fundamentação: a fundamentação mediante o recurso de um dogma.( ALBERT, 1976, p.26)

Ocorre que, como já afirmado, o decisionismo do Estado, pautado tão somente em pré-conceitos dogmáticos e argumentos jurídicos ineficazes, não mais pode prosperar na ótica do Estado Democrático de Direito e na nova interpretação constitucional.

Clara, pois, a necessidade, na decisão do Estado, de argumentos jurídicos válidos, distinguindo premissas e valores, em processo lógico racional, não apenas invocando uma supremacia a priori, o que ensejaria em ausência de fundamentação do ato emanado pelo Estado.

Isso por que, ao afirmar a superioridade a priori de um dos bens em jogo sobre o outro, elimina-se qualquer 
possibilidade de aferição lógica, premiando de antemão, com a vitória completa e cabal, o interesse público envolvido, independentemente das nuances do caso concreto, e impondo o conseqüente sacrifício do interesse privado contraposto. Ao invés da procura racional de solução equilibrada entre o interesse público e o privado implicados no caso, prestigia-se apenas um dos pólos da relação, o que se afigura também incompatível com o principio da hermenêutica constitucional da concordância prática, que obriga o intérprete a buscar, em casos de conflitos, solução jurídica que harmonize, na medida do possível os bens jurídicos constitucionalmente protegidos, sem optar pela realização integral de um, em prejuízo de outro. (SARMENTO, 2005)

\subsection{Argumentos institucionais e não institucionais}

A mera invocação de argumentos que não podem ser controlados subjetivamente v.g interesse público e segurança nacional por não existir uma classificação e validade de tais argumentos, pode levar ao seu uso exacerbado e à arbitrariedade argumentativa, a qual, por sua vez, conduz à nãofundamentação das premissas utilizadas na interpretação jurídica. E, sem uma fundamentação intersubjetivamente controlável, não se concretiza o princípio do Estado de Direito, pela inexistência de dois dos princípios seus: racionalidade do Direito e tutela plena dos Direitos (ÁVILA, 2003).

Com razão são os dizeres de Humberto Ávila de que a não diferenciação dos argumentos utilizados na fundamentação pode trazer arbitrariedades. Eis o seu entendimento:

[...] Com efeito, tanto a ausência de definição dos argumentos utilizados, quanto a falta de diferenciação entre eles inserem, na interpretação jurídica, o germe da ambigüidade e, com ele, a fonte de arbitrariedade Isso porque a mera menção a argumentos, sem a sua necessária justificação, não só exclui a elucidação das premissas, como permite conclusões díspares e até mesmo incomunicáveis entre si.( ÁVILA,2003, p.115)

Destarte, para uma maior objetividade na argumentação das fundamentações jurídicas das decisões, fez-se necessária uma reclassificação dos argumentos jurídicos integrada com uma utilização e valoração móvel e flexível desses mesmos argumentos, para que seja possível discernir os argumentos sem os separá-los por completo, diminuindo a inevitável subjetividade da interpretação sem enrijecer o pensamento para o futuro. Com isso poder-se-á abandonar qualquer simplismo na argumentação jurídica, quer no sentido de reduzir o raciocínio jurídico à pura lógica ou à pura interpretação literal, que no 
sentido de circunscrever a atividade ao mero decisionismo ou a simples ponderação de valores de natureza inexplicada (ÁVILA, 2003).

Pautando nessa necessidade o auto $r$ (2003) classificou os argumentos dividindo-os em institucionais e não institucionais. Os primeiros são aqueles ligados diretamente ao ordenamento jurídico, que podem ser lingüísticos (tanto na linguagem comum quanto na linguagem técnica); sistemáticos; históricos; de Direito comparado e genéticos, relacionados aos trabalhos preparatórios do dispositivo a ser interpretado, ou seja, estão intimamente ligados ao ordenamento jurídico. Esses argumentos foram divididos em Imanentes (Lingüísticos e Sistemáticos) e transcendentes( Históricos e Genéricos). (ÁVILA, 2003).

Em outro norte, os argumentos não institucionais, podem ser entendidos como aqueles que se ligam a qualquer outro elemento que não seja vinculado ao ordenamento jurídico. São argumentos meramente práticos que dependem de um julgamento, feito pelo próprio interprete, sob pontos de vista econômico, político e/ ou ético. Estes argumentos, pelo completo subjetivismo podem ter conseqüências danosas, como por exemplo, a supressão de Direitos e interesses individuais. (ÁVILA, 2003).

Sendo assim, devem prevalecer os argumentos institucionais sobre os não institucionais, posto que aqueles, advindos do próprio ordenamento jurídico, são postos em evidencia no Estado Democrático de Direito, onde figura o império da lei. Os argumentos institucionais possuem como ponto de referência o próprio ordenamento jurídico. É precisamente no ordenamento a que permite uma argumentação intersubjetivamente controlável. Os argumentos não institucionais, ao invés de permitirem um debate objetivamente concebível, apóiam-se exclusivamente em opiniões subjetivas e individuais, contrapondo-se, portanto, às exigências de racionalidade e de determinabilidade da argumentação, ínsitas ao Estado Democrático de Direito. (ÁVILA, 2003).

Com acerto, a afirmação de que os argumentos institucionais devem prevalecer sobre os não institucionais, haja vista que o limite posto no ordenamento jurídico representa o limite traçado pelos princípios da democracia e do Estado de Direito aplicandoo regularmente, pautando-se nos imperativos de clareza e de determinabilidade, o que não ocorre no caso da aplicação de argumentos que não podem ser controlados, pois são exarados a partir do subjetivismo do aplicador da norma.

Como visto, uma interpretação será tanto melhor fundamentada quanto maior for o apoio que receber dos princípios constitucionais, o que preconizado pelo neopositivismo jurídico. Isso porque, estreitando a relação dos argumentos com os princípios fundamentais de determinado 
sistema jurídico, afasta-se de uma justificação

pessoal da interpretação baseada em sistemas de crenças individuais, em favor de uma justificação objetiva fundamentada em pontos de vista objetiváveis e, portanto, de acesso intersubjetivo.

A simples invocação de uma supremacia de uma norma/princípio, não é capaz de ser argumento válido, pois não passa pelo crivo dos princípios norteadores do Estado Democrático de Direito.

Coadunando com este pensamento, trazem-se as palavras de Humberto Ávila, o qual discorre sobre a necessidade de uma fundamentação controlável, a qual somente será possível após o desligamento do uso de concepções pessoais:

[...]O que é incoerente é ininteligível, porque contraditório, fragmentado, desconjutado; o que é incoerente é inteligível. é preciso dar prevalência aos argumentos que se deixam reconduzir aos princípios inerentes ao Estado Democrático de Direito, como são os argumentos lingüísticos e sistemáticos. (...) o que deve ficar claro é que não se pode tolerar, num Estado Democrático de Direito, uma “justificação" que, a pretexto de fundamentar uma interpretação termine por encobri-la. Ora, fundamentar é justamente proporcionar acesso a interpessoal às razões que motivaram determinada decisão de interpretação. Esse esclarecimento é possível e deve ser feito; e deve ser levado a cabo não só pelo poder judiciário, mas também pela doutrina. (ÁVILA, 2003. p. 143,144, 150 e 152)

Por conseguinte, na nova sistemática constitucional, a utilização de argumentação subjetivamente controlável é medida que se impõe.

\subsection{O princípio da proporcionalidade e sua} inaplicabilidade como fundamentação da decisão.

\footnotetext{
Desenvolvemos a idéia segundo a qual a decisão do Estado deve ser fundamentada, usando de argumentos lógicos aptos a fundamentar seu agir.
}

Ocorre que, comumente, verifica-se que vários intérpretes fundamentam suas decisões com a simples aplicação do princípio da proporcionalidade.

Os adeptos desse "método de fundamentação" defendem a idéia de que para a verificação de qual argumento ou princípio argumentativo deve ser aplicado ao caso concreto, ter-se-á que aplicar o princípio da proporcionalidade. Defendem, neste diapasão, a idéia de que este princípio é importantíssimo parâmetro para aferição da constitucionalidade das restrições a Direitos fundamentais, uma vez que estabelecem critérios subjetivos para o controle dos 
conflitos constitucionais. (SARMENTO, 2005).

Para os defensores de tal princípio, a sua aplicação pelo juiz, que executa a justiça material, promove uma ascendência deste em detrimento do legislador sem, contudo, afetar o princípio da separação dos poderes. A este respeito, Paulo Bonavides leciona aduzindo que somente ao juiz é dado o controle e aplicação das normas tendo um espaço de atuação bem mais livre do que o legislador:

[...]Debaixo de certos aspectos, a regra da proporcionalidade produz um controvertida ascendência do juiz(executor da justiça material) sobre o legislador, sem chegar todavia a corroer ou abalar o princípio da separação dos poderes.(...) De último, com a instauração doutrinária do segundo Estado de Direito, o juiz, ao contrário do legislador, atua por um certo prisma num espaço mais livre, fazendo, como lhe cumpre, o exame e controle de aplicação das normas; espaço aberto em grande parte também - sobretudo em matéria de justiça constitucional - pelo uso da noções de conformidade e compatibilidade. Esta última, deveras aberta e maleável, é por isso mesmo mais apta a inserir, enquanto método interpretativo de apoio o princípio constitucional da proporcionalidade. ( BONAVIDES, 2001, p.362 e 363)

A doutrina ${ }^{5}$ sobre o tema tem divido tal princípio em três outros sub-princípios, sendo o da adequação, que exige que as medidas adotadas pelo Poder Público se mostrem aptas a atingir os objetivos pretendidos; o da necessidade ou exigibilidade, que impõe a verificação da inexistência de meio menos gravoso para atingimento dos fins visados; e o da proporcionalidade em sentido estrito, que é a ponderação entre ônus imposto e o benefício trazido, para constatar se é justificável a interferência na esfera dos Direitos do cidadão.

\footnotetext{
${ }^{5}$ A este respeito consultar : BARROSO, Luiz Roberto. Interpretação e Aplicação da Constituição, São Paulo, Saraiva, 1996, p. 209 e BARBOSA JR, José Cláudio Marques. O Princípio da Proporcionalidade como substrato do Estado de Direito. Revista Tributária e de Finanças Públicas. Ano 14, n. 71. São Paulo, RT, 2006, p.282 e 283
}

Pois bem, conforme se abstrai das passagens trazidas, o principio da proporcionalidade tem como premissa a verificação no caso concreto de qual deve ser o interesse aplicado, sendo-o utilizado como argumento jurídico de várias decisões. A aferição de aplicabilidade deverá ser realizada pelo juiz ou pelo administrador no momento de sua atuação. $\mathrm{O}$ cerne da questão cinge-se no fato de que duas poderão ser as conseqüências de tal delegação, I) estar a decisão sujeita ao mero decisionismo do agente público, baseando-se em suas próprias concepções, o que atenta contra o Estado de Direito e a segurança jurídica, pois poderão existir várias decisões para o mesmo caso concreto II) O princípio da separação dos 
poderes ser possivelmente afetado ao delegar ao administrador ou julgador a desvirtuação da manifestação popular anteriormente prevista em lei.

Utilizar, pois, na fundamentação das decisões a invocação do princípio da proporcionalidade torna a decisão vazia e subjetivamente incontrolável.

Isso porque a ponderação de valores não possui caráter de racionalidade, uma vez que trata o Direito como algo meramente atrativo, onde as normas passam a ser negociadas em cada caso concreto, ou seja, por tal princípio da proporcionalidade poderá o agente público optar ou não pela sua aplicação. Isso porque a ponderação de valores visa ao que é bom, ao que é mais bem condicionada a uma determinada cultura, e vivência empírica do julgador. (CATTONI, 2001)

Desta forma, não será incomum a existência de várias decisões judiciais sobre o mesmo fato e sem a devida argumentação jurídica capaz, de ao menos, aceitar este fato, uma vez que as crenças pessoais, os valores, o achar adequado de cada aplicador do Direito, bem como do administrador público, divergem consideravelmente. Por tal razão, não sem fundamentos são as críticas de Muller a este princípio, pois, de fato, ele não traz nenhuma correspondência com as exigências do Estado de Direito, mais precisamente a formação de uma decisão fundamentada com objetividade jurídica e pautada no ordenamento jurídico constitucional, Vejamos o pensamento do autor:

[...]Esse princípio não apresenta nenhum critério material que satisfaça as exigências de clareza das normas, segurança jurídica e de estabilidade dos métodos impostos pelo Estado de Direito. Além disso, como ela supõe a aceitação de axiomas, tais como o reconhecimento da "primazia" ou do "valor superior" de alguns "interesses" ou bens constitucionalmente protegidos, a teoria do balanceamento traz constantemente consigo o perigo de dar a prioridade de forma excessivamente exclusiva, no caso concreto, a uma norma constitucional em detrimento da outra. ( apud MEDAUAR OMMATI, 2007)

Neste ínterim, com a devida utilização de argumentos jurídicos racionais e subjetivamente controláveis seria possível, para a concretização dos princípios do Estado Democrático de Direito, a existência de uma única decisão correta no Direito, como defendido por Dworkin, e decorrente do ideal do Estado de Direito. Esse ideal de integralidade, para ser alcançado, precisa da realização e da confirmação da crença de que o Direito é coerente e que para cada caso haverá uma única decisão correta, como aquela que satisfaz os requisitos de certeza e legitimidade do próprio Direito. E, de fato, para alcançar-se a única decisão não existe fórmula, como por exemplo, a aplicação do 
princípio da proporcionalidade e seus subprincípios, mas sim, deverá emergir dos fatos e fundamentos trazidos pelas partes interessadas, inerentes a qualquer Constituição em um Estado Democrático de Direito, quais sejam, contraditório, ampla defesa e devido processo legal. (MEDAUAR OMMATI, 2007).

Realmente, a norma a ser aplicável não pode ser alvo de um arbítrio imposto pelo princípio da proporcionalidade, mas sim deve ser escolhida após a participação de todos os interessados, com argumentos jurídicos lógicos e controláveis, que poderão expor suas idéias, vontades e convicções, o que é previsto na Constituição da República de 1988. Neste mesmo sentido, o pensamento de José Emílio Medauar Ommati:

[...]Assim o ato de escolha da norma não é um ato arbitrário, mas se dá em decorrência do que foi reconstruído no curso do processo. É dizer: a situação de aplicação só pode se tornar clara para o aplicador do Direito se as partes puderem, em igualdade de condições, em simétrica paridade, apresentar os diversos lados da questão. E isso só pode ser feito através do princípio do contraditório, característica essencial de qualquer processo. (MEDAUAR OMMATI, 2007, p.124)

E assim deve ser em todas as atividades do Estado, não restringindo-se apenas ao âmbito judicial. Isso porque em uma concepção ampla, todas as vezes que houver um procedimento realizando-se em contraditório, caracterizado não apenas pelo dizer e contradizer, mas sim pela igualdade de oportunidades no processo, a igualdade de tratamento e de liberdade de todos perante a lei, garantindo-se assim o instituto do devido processo ter-se-á a verificação de um processo. $^{6}$

Alude-se, ainda, que o não agir de forma a propiciar a construção da norma a ser aplicável por um processo em contraditório, deixando-a apenas na vontade subjetiva do julgador, dará a este a possibilidade de inovar no ordenamento jurídico, o que lhe é vedado pela ordem constitucional em vigor, a qual, seguindo as idéias de Montesquieu, "repartiu" o poder do Estado em três esferas de atuação. Por tal princípio, cada um dos entes detém competências próprias e exerce papel fundamental para a manutenção do equilíbrio da atuação do Estado.

\footnotetext{
${ }^{6}$ Sobre o instituto do devido processo e os princípios institutivos do processo consultar: MADEIRA, Dhenis Cruz. Processo de Conhecimento e Cognição: uma inserção no Estado Democrático de Direito. Curitiba, Juruá, 2008.
} 


\section{CONSIDERAÇÕES FINAIS}

Destarte, restou comprovado que na nova interpretação constitucional, denominada de pós-positivismo, o intérprete deve pautar de forma racional, sempre valorando os princípios inerentes ao Estado Democrático de Direito e aplicando-os ao caso, não mais vinculado ao texto frio da lei. Mesmo assim, após o advento da nova interpretação constitucional, verifica-se que ainda hoje prevalece no atuar do Estado a ausência da concepção do que seja o "novo paradigma" previsto na Constituição da Republica de 1988, posto que, ainda constatamos decisões em meras invocações de dogmas, ineficazes para a validade do ato.

Neste ínterim, a Constituição prescreve uma tarefa de concretização de normas que não guardam similitude com a atividade de execução das leis. Existe significativa diferença entre o administrador (poder executivo), o julgador (poder judiciário) e o legislador (poder legislativo), bem como entre o ato administrativo, judicial e legislativo. A aplicação a priori de argumentos ilógicos, como vimos, delega ao julgador e ao administrador a possibilidade de agir por concepções próprias, avaliando a necessidade, a adequação e a proporcionalidade de seus atos, o que muitas vezes pode afigurar-se como forma desmembrada de legislar, o que é plenamente vedado da Constituição Nacional.
Assim, para a devida atuação do Estado, faz necessário que cristalize a concepção do Estado de Direito, com a aplicação de seus princípios, em decisões sempre fundamentadas. Uma das formas de validação do atuar do Estado seria a argumentação lógica de seus atos, o que é possível por meio da aplicação do método dedutivo, como preconizado por Hans Albert, ou mesmo pela hierarquia dos argumentos institucionais, como ensinado por Humberto Ávila.

O que não mais se pode admitir é a invocação de argumentos não institucionais (como interesse público, bem comum e moral pública), bem como de um suposto princípio da proporcionalidade, para fundamentar as decisões do Estado, aplicando pré-conceitos impossíveis de serem controlados subjetivamente. Deve, pois, reinar, no Estado Democrático de Direito, uma interpretação constitucional e argumentação lógica apta a fundamentar a decisão administrativa e jurídica do Estado, levando-se em conta os princípios do Estado Democrático de Direito.

\section{REFERÊNCIAS}

ALBERT, Hans. Tratado da Razão Crítica. Rio de Janeiro, Tempo Brasileiro, 1976.

ARANHA, Maria Lúcia de Arruda. Filosofando: introdução à filosofia. $2^{\mathrm{a}} \mathrm{ed}$, São Paulo, Moderna, 1993. 
ÁVILA, Humberto Bergman. Argumentação Jurídica e a Imunidade do Livro Eletrônico, in Temas de Interpretação de Direito Tributário(org. Ricardo Lobo Torres). Ed. Renovar, Rio de Janeiro, 2003.

BARROSO, Luiz Roberto. Interpretação e Aplicação da Constituição, São Paulo, Saraiva, 1996, p. 209 e BARBOSA JR,.

BARROSO, Luis Roberto e BARCELOS, Ana Paula de, $\mathbf{O}$ começo da História in SAMPAIO, José Adércio Leite(coord), Crises e Desafios da Constituição: perspectiva critica da teoria e das práticas constitucionais brasileiras. Belo Horizonte, Del Rey, 2003.

FERRAZ JÚNIOR Tércio Sampaio. Interpretação e Estudos da Constituição de 1988. São Paulo, Atlas, 1990.

SARMENTO, Daniel. Interesses Públicos vs. Interesses Privados na Perspectiva da teoria e da filosofia constitucional in SARMENTO DANIEL(org.). Interesses Públicos versus Interesses Privados: desconstruindo o princípio da supremacia do interesse público. Rio de Janeiro, Editora Lumen Júris, 2005.

MADEIRA, Dhenis Cruz. Processo de Conhecimento e Cognição: uma inserção no Estado Democrático de Direito. Curitiba, Juruá, 2008.

MARQUES, José Cláudio. O Princípio da Proporcionalidade como substrato do Estado de Direito. Revista Tributária e de Finanças Públicas. Ano 14, n. 71. São Paulo, RT, 2006, p.282 e 283

MADAUAR OMMATI, José Emílio. O Princípio da Proporcionalidade e a ordem concreta de valores publicado na Revista de
Direito Constitucional e Internacional, ano 15, n.58; São Paulo, Revista dos Tribunais, 2007. 